\title{
Digital rectal stimulation associated with psychiatric disorders as a rare reason of solitary rectal ulcer in children and adolescents: a case series
}

\author{
Fatih Hilmi Cetin ${ }^{\circledR}$, Halil Haldun Emiroglu ${ }^{2 \oplus}$, Saliha Calisir ${ }^{3 \oplus}$, Serhat Turkoglu ${ }^{1 \oplus}$ \\ 'Selcuk University, Faculty of Medicine, Department of Child and Adolescent Psychiatry, Konya - Turkey \\ ${ }^{2}$ Selcuk University, Faculty of Medicine, Department of Pediatric Gastroenterology, Hepatology and Nutrition, Konya - Turkey \\ ${ }^{3}$ Konya Training and Research Hospital, Department of Psychiatry, Konya - Turkey
}

\begin{abstract}
Solitary rectal ulcer syndrome is one of the rare causes of rectal bleeding in children and adolescents. Traumatic and ischemic mucosal injury is the main cause of its etiopathogenesis. A rare but important cause of traumatic mucosal injury is digital rectal stimulation. It is known that digital rectal stimulation is used in order to increase intestinal motility and to reduce the feeling of inadequate defecation. In this study, it was emphasized that digital rectal stimulation can be seen as a consequence of psychiatric disorders, and with proper psychiatric interventions, digital stimulation behavior and solitary rectal ulcer syndrome can be improved. Moreover, the importance of a cooperation between gastroenterologist and psychiatrist in such cases has been stressed.
\end{abstract}

Keywords: Children and adolescents, digital rectal stimulation, mental illness, rectal bleeding, solitary rectal ulcer

\section{INTRODUCTION}

Solitary rectal ulcer syndrome (SRUS) is one of the rare causes of rectal bleeding in children/adolescents (1). Its prevalence is known to be 1 in 100.000 , and the condition is much less common in children (2). Rectal mucosal injury secondary to ischemia and trauma plays a key role in its etiopathogenesis (3). A rare cause of trauma to the rectal mucosa is the stimulation of the anus with a finger (digital rectal stimulation: DRS) by a child or adolescent (1). In this report, four cases referred to the child/adolescent psychiatry outpatient clinic by pediatric gastroenterology due to SRUS based on DRS will be examined. All patients and their families were informed that their cases would be published as case reports and their written informed consent was obtained.

\section{CASES}

\section{Case 1}

A 16-year-old male patient admitted to the gastroenterology outpatient clinic with rectal bleeding and painful defecation was diagnosed with SRUS. It was discovered in his anamnesis that he was inserting a finger into his anus to drain bowel contents 2-3 times per week. He was referred to the child/adolescent psychiatry outpatient clinic. It was learned that the

How to cite this article: Cetin FH, Emiroglu HH, Calisir S, Turkoglu S. Digital rectal stimulation associated with psychiatric disorders as a rare reason of solitary rectal ulcer in children and adolescents: a case series. Dusunen Adam The Journal of Psychiatry and Neurological Sciences 2019;32:352-354.

Correspondence: Fatih Hilmi Cetin, Selcuk University, Faculty of Medicine, Department of Child and Adolescent Psychiatry, Konya - Turkey Phone: +90 3322245082 E-mail: fatihhilmicetin@gmail.com 
patient was the youngest of the three siblings, left school when he was in grade 9 to continue his education in outdoor teaching high school, and lived with his nuclear family of average socioeconomic status. He described himself as a person who made sudden decisions (stating that the reason for dropping out of school was also related to this propensity), while he would later regret, tended to fail at anger management, and damage himself and objects around him when getting angry. His mother stated that he was always a restless child and had problems such as being easily frustrated, losing himself when he got angry, hating to study (for which reason he had dropped out of school), and being argumentative and vindictive. Developmental history, medical and family history did not show any remarkable characteristics. In the mental examination, the patient was restless and displayed an irritable mood, anxious emotions, and a defensive communication style. In the psychometric evaluation, lack of self-esteem and signs of attention deficit hyperactivity disorder (ADHD) were found. With a semi-structured diagnostic interview, "Schedule for Affective Disorders and Schizophrenia for School Aged Children - Present and Life Time Version-Turkish Adaptation (K-SADS-PL)", the patient was diagnosed with ADHD and Oppositional Defiant Disorder (ODD). Subsequently, parental education and supportive psychotherapy were recommended for behavioral problems; in addition, risperidone $1 \mathrm{mg}$ /day was initiated. In the first month of the treatment, digital rectal stimulation disappeared. SRUS symptoms and endoscopic appearance improved. In the third month of follow-up, an increase in social and occupational functions was observed with adding methylphenidate to the treatment of ADHD. The patient's treatment still continues with a combination of methylphenidate and risperidone.

\section{Case 2}

A 14 -year-old male patient in $8^{\text {th }}$ grade presented with SRUS caused by DRS. It was learned that the patient was the 3 rd of 4 siblings, and one of his siblings was attending a special education program for handicapped children because of mild mental retardation. The patient, who came in with his sister, had previously consulted another psychiatrist with a complaint of irritability. Back then, the psychiatrist had suggested a treatment but the family had not accepted it. When he arrived at the outpatient clinic, he was using a crutch because he had broken his ankle while running at school. The patient's school success was moderate and there were behavioral problems such as being easily frustrated and a tendency to violence leading to disciplinary punishment. He stated that he carried out digital rectal stimulation once or twice a week, particularly when he was angry. He said that it was painful but calming at the same time. With K-SADS-PL and psychometric evaluations, he was diagnosed with ADHD. Risperidone $0.5 \mathrm{mg} /$ day and supportive psychotherapeutic interviews were initiated for behavioral problems and DRS. Similar to the first case, in the first month both ADHD and SRUS symptoms and the endoscopic appearance improved.

\section{Case 3}

A 15-year-old male patient in 10th grade presented with SRUS caused by DRS. School success was moderate. He said he could not use the school toilets because they were dirty and he did not feel safe because of peer bullying. For this reason, he was defecating at home in the evenings, trying to get the feces out with his finger because they had hardened. He indicated that the process was painful but worth the feeling of his bowels being completely empty. Anxious emotions and increased psychomotor activity were noted in the mental examination. With K-SADS-PL and psychometric evaluations, he was diagnosed with generalized anxiety disorder (GAD) and ADHD. Cognitive behavioral therapy and risperidone $0.5 \mathrm{mg} /$ day plus atomoxetine $50 \mathrm{mg} /$ day were initiated. In the first month of follow-up, SRUS symptoms and endoscopic appearance improved and there was also a marked clinical improvement in ADHD and GAD.

\section{Case 4}

An 8-year-old female patient in $2^{\text {nd }}$ grade presented because of SRUS caused by DRS. In the examination, she was introverted and avoiding eye contact. During the examination, she could not stay alone with the psychiatrist and was hiding behind her mother. In the child's behavior profile, the extremely intrusive attitudes of parents were thought to play a key role. With K-SADS-PL and psychometric evaluations, the patient was diagnosed with social phobia with prominent behavioral inhibition. Treatment was started with fluoxetine $5 \mathrm{mg} /$ day gradually increased to $15 \mathrm{mg} /$ day. In the course of the treatment, the girl stated that she must not have stool stains on her underwear because her mother gets very angry. For this reason, she indicated that she had to discharge the bowels by removing the remaining pieces of poop using DRS. Cognitive-behavioral therapy for obsessive-compulsive 
thoughts and behaviors and parent education were added. After the second month of treatment, remarkable improvements in behavioral inhibition and SRUS symptoms were observed.

\section{DISCUSSION}

In this study, four cases of SRUS associated with DRS were reported. This report is novel in that it presents the relationship between SRUS and psychiatric disorders in a children/adolescent population.

The diagnosis of solitary rectal ulcer syndrome is based on an endoscopic evaluation by the clinician followed by an examination of the histologic findings. $(2,4)$. While being rare, differential diagnosis with other medical conditions that can often cause rectal bleeding, such as amebiasis, inflammatory bowel disease, and chronic ischemic colitis, should not be forgotten (5). In our cases, clinical appearance was matching with SRUS and endoscopic and histopathological evaluations were done for final diagnosis. However, factors that are known to cause SRUS have been excluded, and clinicians came to the conclusion that DRS lead to traumatic mucosal injury and eventually to SRUS in these patients. As in our cases, a rare cause of mechanical traumatic mucosal damage is DRS $(1,2)$. Digital rectal stimulation is done to increase motility or sometimes due to a feeling of inadequate defecation. All of our cases stated that they performed DRS for the latter reason. In addition, three patients stated that they felt a kind of spiritual relief, and one of them reported that he felt pleasure in so doing. Self-mutilative behaviors for emotional regulation can be seen in cases of ADHD and ODD, especially in patients whose impulsivity is prominent $(6,7)$. Self-mutilative behaviors lead to the release of endorphins, providing relief from painful memories and emotions $(6,8)$. In our opinion, the emotional regulation with pharmacotherapy and psychotherapy provided improvement in self-mutilative behaviors including DRS in our patients. Sometimes extremely intrusive parents, especially those who are meticulous about hygiene and order, can cause various problems in children with their supervisory and controlling behaviors that start with the toilet training process (9). One of our patients, being overwhelmed by the control through her intrusive parents, was trying to maintain emotional regulation with DRS. On the other hand, our patient was trying to be completely clean as her mother wanted her to be.

In conclusion, to determine DRS in the etiology of SRUS is only possible by excluding other causes and by the clinician's sensitivity. It is important in terms of identifying the underlying psychopathology to consult child/adolescent psychiatry in addition to gastroenterological treatment.

\begin{tabular}{|c|c|c|}
\hline \multicolumn{2}{|c|}{ Contribution Categories } & Author Initials \\
\hline \multirow{4}{*}{ Category 1} & Concept/Design & F.H.C., H.H.E. \\
\hline & Literature review & S.C. \\
\hline & Data analysis/Interpretation & S.C., F.H.C. \\
\hline & Case follow-up (if applicable) & F.H.C. \\
\hline \multirow{2}{*}{ Category 2} & Drafting manuscript & F.H.C. \\
\hline & Critical revision of manuscript & S.T., H.H.E. \\
\hline Category 3 & Final approval and accountability & S.T., F.H.C., S.C., H.H.E. \\
\hline \multirow{2}{*}{ Other } & Technical or material support & H.H.E. \\
\hline & Supervision & S.T. \\
\hline
\end{tabular}

Informed Consent: Written informed consent was obtained from the patients.

Peer-review: Externally peer-reviewed.

Conflict of Interest: The authors declared no conflict of interest.

Financial Disclosure: None declared.

\section{REFERENCES}

1. Dehghani SM, Malekpour A, Haghighat M. Solitary rectal ulcer syndrome in children: a literature review. World J Gastroenterol 2012; 18:6541-6545. [CrossRef]

2. Perito ER, Mileti E, Dalal DH, Cho SJ, Ferrell LD, McCracken M, Heyman MB. Solitary rectal ulcer syndrome in children and adolescents. J Pediatr Gastroenterol Nutr 2012; 54:266-270.

3. Keshtgar AS. Solitary rectal ulcer syndrome in children. Eur J Gastroenterol Hepatol 2008; 20:89-92. [CrossRef]

4. Urganci N, Kalyoncu D, Eken KG. Solitary rectal ulcer syndrome in children: a report of six cases. Gut Liver 2013; 7:752-755.

5. Tjandra JJ, Fazio VW, Petras RE, Lavery IC, Oakley JR, Milsom JW, Church JM. Clinical and pathologic factors associated with delayed diagnosis in solitary rectal ulcer syndrome. Dis Colon Rectum 1993; 36:146-153. [CrossRef]

6. Baiden P, Stewart SL, Fallon B. The role of adverse childhood experiences as determinants of non-suicidal self-injury among children and adolescents referred to community and inpatient mental health settings. Child Abuse Negl 2017; 69:163-176.

7. Chamberlain SR, Redden SA, Grant JE. Associations between self-harm and distinct types of impulsivity. Psychiatry Res 2017; 250:10-16. [CrossRef]

8. Kirtley OJ, O'Carroll RE, O'Connor RC. The role of endogenous opioids in non-suicidal self-injurious behavior: methodological challenges. Neurosci Biobehav Rev 2015; 48:186-189. [CrossRef]

9. Bender PK, Somhovd M, Pons F, Reinholdt-Dunne ML, Esbjorn $\mathrm{BH}$. The impact of attachment security and emotion dysregulation on anxiety in children and adolescents. Emot Behav Diffic 2015; 20:189-204. [CrossRef] 